\title{
Sağ Ventrikül Çıkış Yolu Darlıklarının Tamirinde Homogreft ve Contegra Greft Kullanılan Hastaların Sağ Kalımının Karşılaştırılması
}

\section{Comparison of the Survival of Patients who Underwent Right Ventricular Outflow Tract Repair with Homografts versus Contegra Grafts}

\author{
Dilşad Amanvermez Şenarslan ${ }^{1 *}$, Emin Alp Alayunt ${ }^{2}$ \\ ${ }^{1}$ Manisa Celal Bayar Üniversitesi Tıp Fakültesi, Kalp ve Damar Cerrahisi Anabilim Dalı, Manisa, Türkiye \\ ${ }^{2}$ Özel Gazi Hastanesi, Kalp ve Damar Cerrahisi Bölümü, İzmir, Türkiye \\ e-mail: damanvermez@yahoo.com, alayunt@gmail.com \\ ORCID: 0000-0002-3316-6707 \\ ORCID: 0000-0003-4284-0289 \\ *Sorumlu yazar/ Corresponding Author: Dilşad Amanvermez Şenarslan
}

Gönderim Tarihi / Received: 11.01.2021

Kabul Tarihi / Accepted: 18.01.2021

DOI: $10.34087 /$ cbusbed. 857969

\section{$\ddot{\mathbf{O} z}$}

Giriş ve Amaç: Homogreftler veya ksenogreftler sağ ventrikül çıkış yolu (RVOT) darlıklarının tedavisinde günümüzde en sık kullanılan materyallerdir. Çalışmanın amacı RVOT tamirlerinde homogreft ve Contegra ${ }^{\circledR}$ Greft (ksenogreft) kullanılan hastaların mortalite oranlarını belirlemek ve sağ kalımlarını karşılaştırmaktır. Çalışmanın ikincil amacı ise mortalite için risk faktörlerinin belirlenmesidir.

Gereç ve Yöntemler: Çalışmaya üçüncü basamak sağlık kuruluşumuzda son yedi yılda RVOT darlığı nedeniyle homogreft veya Contegra ${ }^{\circledR}$ Greft kullanılarak RVOT rekonstrüksüyonu uygulanan hastalar dahil edilmiştir. Toplam 71 hastanın; 18'ine homogreft $(\% 25,4)$ ve 53'üne $(\% 74,6)$ ise Contegra ${ }^{\circledR}$ Greft ile RVOT rekonstrüksüyonu uygulanmıştır. Çalışma için yerel etik kurul izni alınmıştır.

Bulgular: RVOT darlığının en sık etiyolojik sebebi Fallot Tetralojisiydi. Contegra ${ }^{\circledR}$ Greft grubunun yaş ortalaması ve kullanılan greft çapları ( $\mathrm{t}$ test, $\mathrm{p}<0,01$ ) daha küçüktü. Grupların kross-klemp ve kardiyopulmoner bypass süreleri, hastanede yatış süreleri benzerdi. Grupların total mortalite oranları arasında farklılık yoktu (Fisher Exact Test, $\mathrm{p}=0,17)$. Contegra ${ }^{\circledR}$ Greft grubu için tahmin edilen ortalama sağ kalım süresi 5,6 yılken, homogreft grubunda yaklaşık 4 yıldır. Contegra ${ }^{\circledR}$ Greft grubunda 1 yıllık sağ kalım \%88 iken 5 yılda oran \%83’e düşmektedir (Kaplan-Meier metodu). Multivariate Cox regresyon analizinde tanı, redo operasyonlar, cinsiyet, vücut yüzey alanı mortalite için risk oluşturmazken, 1 yaş altında olmak mortalite için bağımsız bir risk faktörüydü.

Sonuç: RVOT darlıklarının tamirinde Contegra ${ }^{\circledR}$ Greftler, homogreftlerin iyi bir alternatifidir. Erken ve orta dönemdeki benzer fonksiyonel kapasite ve sağ kalım oranları nedeniyle hastaya uygun homogrefte ulaşılamadığında Contegra ${ }^{\circledR}$ Greftler RVOT rekonstrüksüyonunda güvenle kullanılabilir.

Anahtar kelimeler: Contegra ${ }^{\circledR}$ heterogreft, Homogreft, Ksenogreft, Sağ ventrikül çıkış yolu, Sağ kalım.

\section{Abstract}

Objective: Homografts or xenografts are the most commonly used materials in the treatment of right ventricular outflow tract (RVOT) stenosis. The aim of the study is to determine the mortality rates and compare the survival rates of patients who underwent RVOT repair by using homograft and Contegra ${ }^{\circledR}$ Graft (xenograft). The secondary endpoint of the study was to determine the risk factors for mortality.

Materials and Methods: We included 71 patients who are operated in last seven years in our tertiary healthcare service for RVOT reconstructions by using homograft or Contegra ${ }^{\circledR}$ Graft. Homograft was applied 18 of them (24.5\%) and Contegra ${ }^{\circledR}$ Graft was applied 53 of them (74.6\%). Local ethical committee approved the study. 
Results: Tetralogy of Fallot was the most common etiological cause of RVOT stenosis. The average age and the graft diameters that used were in smaller size $(t$ test, $\mathrm{p}<0.01)$ in Contegra ${ }^{\circledR}$ Graft group. Cross-clamp and cardiopulmonary bypass times and duration of the hospitalization of the groups were similar. There was no difference between the total mortality rates of the groups (Fisher Exact Test, $\mathrm{p}=0.17$ ). The estimated median survival for the Contegra ${ }^{\circledR}$ Graft group is 5.6 years, while in the homograft group it is about 4 years. Survival rates in the Contegra ${ }^{\circledR}$ Graft group, was $88 \%$ at 1 year, and the rate decreased to $83 \%$ at 5 years (Kaplan-Meier method). In Multivariate Cox regression analysis, the diagnosis, redo operations, gender, body surface area did not pose a risk for mortality, while being under 1 year of age was an independent risk factor for mortality.

Conclusion: Contegra ${ }^{\circledR}$ Graft is a good alternative to homograft for the repair of RVOT obstructions. Because of similar functional capacity and survival rates of the patients in early and mid-term, Contegra ${ }^{\circledR}$ Grafts can be safely used for RVOT reconstruction when a homograft suitable to the patient is not available.

Keywords: Contegra ${ }^{\circledR}$ heterograft, Homograft, Right ventricular outflow tract (RVOT), Survival, Xenograft.

1. Giriş
Sağ ventrikül çıkış yolu (RVOT), kalbin sağ ventrikül ve pulmoner arter bifurkasyonu arasinda yer alan bölümüdür, sağ ventrikülün infundibulum kısmı, pulmoner annulus, pulmoner kapak ve ana pulmoner arteri içerir. RVOT darlığı nedeni izole pulmoner stenoz (PS) veya pulmoner atrezi olabileceği gibi Fallot Tetralojisi, truncus arteriosus, büyük arterlerin transpozisyonu, çift çıkışlı sağ ventrikül veya çift çıkışlı sol ventrikül gibi çeşitli konjenital malformasyonların bir komponenti olarak da gözlenebilir. RVOT darlıkları tüm konjenital kalp hastalıkları içerisinde (izole veya diğer anomalilerle birlikte) \%25-30 oranında görülmektedir ve RVOT darlıklarının \%80-90'ında ise izole PS gözlenmektedir [1,2]. RVOT rekonstrüksüyonu ile sağ ventrikül ve pulmoner arter devamlılığı anatomik, morfolojik ve hemodinamik olarak yeniden yapılandirılmaktadır.

RVOT tamirinde kullanılacak ideal konduitten beklenen, uzun süre dayanması, her boyutta ve kolay temin edilebilmesi, kapak fonksiyonlarını uzun süre koruması, cerraha dikiş kolaylığı sağlaması, bükülebilir ve yırtılmalara karşı dayanıklı olması, enfeksiyonlara dirençli olması, trombojenik olmaması, büyüme potansiyelinin olması ve maliyetinin düşük olmasıdır. $\mathrm{Bu}$ amaçla günümüzde en yaygın kullanılan konduit materyalleri homogreftler ve Contegra ${ }^{\circledR}$ Greftlerdir. Domuzdan elde edilen xenogreftlerin, Contegra ${ }^{\circledR}$ greftler ve homogreftlere göre daha erken bozulduğu önceki çalışmalarda gösterilmiştir [3-4].

RVOT tamiri için ilk başarılı kapaklı homogreft kullanımı 1966'da Ross ve Sommerville tarafından gerçekleştirilmiştir. $\mathrm{O}$ zamandan beri kriyoprezerve homogreftlerle RVOT rekonstrüksüyonu birçok araştırmacı tarafından önerilmiş altın standart tedavidir [5-8]. Homogreftlerin en önemli avantajı antikoagülan kullanımı gerektirmemesi, cerrahi dikiminin kolay olması, bükülebilirliği, enfeksiyonlara dirençli olması ve dayanıklılığıdır. Homogreftlerin ortalama 15 yıl dayanması beklenir $[8,9]$. Birçok çalışmada pulmoner homogreftlerin aortik homogreftlere göre daha dayanıklı olduğu gösterilmiştir [10,11]. Ancak infantlara uygun küçük çaptaki homogreftlerin kolay bulunamaması nedeniyle alternatif materyallere ihtiyaç duyulmuştur. Domuz veya sığır perikardından ksenogreftler, domuz aort rootları ve Contegra ${ }^{\circledR}$ greftler RVOT tamirlerinde kullanılmıştır. Son yıllarda ise Politetrafluoroetilen (PTFE) kapaklı konduitler de kullanılmaktadır [12]. Contegra ${ }^{\circledR}$ Greft $\left(\right.$ Contegra $^{\circledR}$, Medtronic Inc, Mineapolis MN, USA), gluteraldehidle fikse edilmiş sığır juguler veninden elde edilen, içerisinde doğal olarak üç venöz kapakçık bulunan konduittir. En önemli avantaj1 12 mm'den-22 mm'ye her boyuna kolay ulaşılabilir olmasıdır. Ayrıca konduit yumuşak ve yeterince bükülebilir olduğundan cerraha dikiş kolaylığı sağlar $[13,14]$. Çalışmanın amacı RVOT tamirlerinde homogreft ve Contegra ${ }^{\circledR}$ Greft (ksenogreft) kullanılan hastaların mortalite oranlarını belirlemek ve să kalımlarını karşılaştırmaktır. Çalışmanın ikincil amacı ise mortalite için risk faktörlerinin belirlenmesidir.

\section{Materyal ve Metot}

Çalışma için yerel etik kurul izni alınmıştır. Çalışmaya üçüncü basamak sağlık kuruluşumuzda son yedi yılda RVOT darlığı nedeniyle homogreft veya Contegra ${ }^{\circledR}$ Greft kullanılarak RVOT rekonstrüksüyonu uygulanan hastalar dahil edilmiştir ve retrospektif olarak dosya kayıtları incelenmiştir. Toplam 71 hastanın; 18'ine homogreft $(\% 25,4)$ ve 53 'üne $(\% 74,6)$ ise Contegra ${ }^{\circledR}$ Greft ile RVOT rekonstrüksüyonu uygulanmıştır. Tüm operasyonlar aynı cerrahi ekip tarafindan gerçekleştirilmiştir. Operasyonlar standart medyan sternotomi ile yapılmış, hafif hipotermide kardiyopulmoner bypass eşliğinde gerçekleştirilmiştir ve kan kardiyoplejisi kullanılmıştır. Homogreftler kliniğin bünyesinde bulunan homogreft laboratuvarında hazırlanmıştır ve öncelikli olarak pulmoner homogreftler tercih edilmiştir. Tüm hastalar postoperatif 1., 3. ve 6 . ayda ve sonrasında yıllık poliklinik ve ekokardiyografi kontrolleri ile takip edilmiştir.

İstatistiksel analizler için SPSS software 17.0 bilgisayar program kullanılmıştır. Grupların demografik verilerin ve kategorik değiş̧kenlerin karşılaştırılmasında $\mathrm{x}^{2}$ testi ve Fisher's Exact Test kullanılmıştır. Gruplar arasındaki parametrik verilerin karşılaştırılmasında independent samples $\mathrm{t}$ test kullanılmıştır. Her iki grubun sağ kalım oranları Kaplan-Meier metodu ile karşılaştırılmıştır. RVOT tamiri sonrası mortalite için bağımsız risk faktörleri Multivariate Cox regression analizi ile araştırılmıştır.

\section{Bulgular ve Tartışma \\ 3.1 Bulgular}


RVOT tamirleri 18 hastada homogreft ile $(\% 25,4)$ ve 53 hastada Contegra ${ }^{\circledR}$ Greft ile $(\% 74,6)$ gerçekleştirilmiştir. RVOT rekonstrüksiyonunun en sik etiyolojik sebebi Fallot Tetralojisiydi, diğer patolojilerin dağılımı Tablo 1'de gösterilmiştir. 71 hastadan 7'si ölmüş $(\% 9,8)$ ve 7'sinin izlemi takipte kaybedilmiştir ve sağ kalan 57 hastanın izlemi devam etmiştir.
Hastaların grupları arasında cinsiyet dağılımı açısından fark yoktu (Fisher exact test, $\mathrm{p}=0,75$ ). Operasyondaki kross-klemp süresi, kardiyopulmoner bypass süresi her iki grupta benzerdi. Tablo 1'de hastaların demografik verileri ve operasyonla ilgili özellikleri gösterilmiştir.

Tablo 1. Hastaların Demografik verileri ve Klinik Özellikleri

\begin{tabular}{|c|c|c|c|c|}
\hline Gruplar & Homogreft & Contegra ${ }^{\circledR}$ Greft & Total & $\begin{array}{l}\text { İstatistik yöntem, } \mathrm{P} \\
\text { değeri }\end{array}$ \\
\hline Erkek / Kadın (n), (\%) & $\begin{array}{l}9 / 9,(\% 12,7 \\
/(\% 12,7)\end{array}$ & $\begin{array}{l}30 / 23,(\% 42,2 \\
1 \% 32,3)\end{array}$ & $\begin{array}{l}39 / 32,(54,9 \% \\
/ 45,0 \%)\end{array}$ & $\begin{array}{l}\text { Fisher exact test, } \\
\mathrm{p}=0,75\end{array}$ \\
\hline Yaş, ortalama \pm S.D. (yıl) & $17,3 \pm 16$ & $3,8 \pm 3,7$ & $7 \pm 11,7$ & T test, $\mathrm{p}=0,008$ \\
\hline Vücut yüzey alanı (BSA) $\left(\mathrm{m}^{2}\right)$ & $1,19 \pm 0,47$ & $0,61 \pm 0,3$ & $0,76 \pm 0,43$ & T test, $\mathrm{p}<0,001$ \\
\hline \multicolumn{5}{|c|}{$\begin{array}{l}\text { RVOT Rekonstrüksiyonu gerektiren } \\
\text { konjenital kalp hastalığı (n), (grup içindeki } \\
\text { \%) }\end{array}$} \\
\hline Fallot Tetralojisi & 6 & 29 & & \\
\hline Pulmoner Stenoz veya Atrezi & 10 & 3 & $13(\% 18,3)$ & \\
\hline DORV & 2 & 7 & $9(\% 12,7)$ & \\
\hline Corrected TGA & 0 & 7 & $7(\% 9,9)$ & \\
\hline Truncus Arteriosus & 0 & 5 & $5(\% 7)$ & \\
\hline Ross Operasyonu, Aort Darlığı & 0 & 1 & $1(\% 1,4)$ & \\
\hline DOLV & 0 & 1 & $1(\% 1,4)$ & \\
\hline İmplante edilen konduit çapı (mm) & $21,9 \pm 2$ & $15,2 \pm 2$ & & T test, $\mathrm{P}<0,001$ \\
\hline Redo operasyonlar (n), (tüm gruptaki \%) & 8 & 4 & $12(\% 16,9)$ & $\begin{array}{l}\text { Fisher exact test, } \\
\mathrm{p}=0,001\end{array}$ \\
\hline Kardiyopulmoner Bypass Süresi (dk) & $106,9 \pm 31$ & $106,6 \pm 25$ & & T test, $\mathrm{p}=0,97$ \\
\hline Kross-klemp süresi (dk) & $78,1 \pm 38$ & $88,5 \pm 23$ & & $\mathrm{~T}$ test, $\mathrm{p}=0,30$ \\
\hline
\end{tabular}

DORV: Çift çıkışlı sağ ventrikül, DOLV: Çift çıkışlı sol ventrikül, TGA: Büyük Arterlerin Transpozisyonu, dk: dakika, mm: milimetre, $\mathrm{m}^{2}$ : metrekare

Redo operasyonlar istatistiksel olarak homogreft (8 hasta) kullanilan grupta, Contegra ${ }^{\circledR}$ Greft (4 hasta) grubuna göre daha fazla sayıdaydı (Fisher exact test, $\mathrm{p}=0,001)$. Bu durum homogreftlerin küçük çaptaki boyutlarının daha sınırlı olmasıyla ilişkilendirilmiştir. Hastalarda uygun çapta homogreft bulunamadığında daha ulaşılabilir olan ve $12 \mathrm{~mm}$ 'e kadar küçük çapları mevcut olan Contegra ${ }^{\circledR}$ Greft tercih edilmiştir. Bu sebeple homogreft grubunda yaş ortalaması, kilo ve vücut yüzey alanı daha fazlaydı.

Yoğun bakımda kalış süresi homogreft grubunda daha azken ( $\mathrm{t}$ test, $\mathrm{p}=0,04)$ ilk 30 günde görülen komplikasyonlar (Fisher exact test, $\mathrm{p}=0,38$ ) ve hastanede yatış süreleri ( $\mathrm{t}$ test, $\mathrm{p}=0,18$ ) her iki grupta benzer oranda gözlenmiştir (Tablo 2). Grubun tamamında görülen komplikasyonlar; 6 hastada pnömoni $(\% 8,4), 5$ hastada düşük kardiyak debi $(\% 7,5), 2$ hastada kalıcı AV blok $(\% 2,8), 2$ hastada geçici AV blok $(\% 2,8), 2$ hastada uzamış mekanik ventilasyon $(\% 2,8), 2$ hastada hemoraji $(\% 2,8), 1$ hastada plevral efüzyon $(\% 1,4), 1$ hastada perikardiyal efüzyon $(\% 1,4)$ ve 1 hastada şilotoraks $(\% 1,4)$ şeklindedir. Postoperatif komplikasyonların dağılımı Tablo 2'de gösterilmiştir. Düşük kardiyak debi gelişen hastaların hepsi Contegra ${ }^{\circledR}$ Greft grubunda yer almaktaydı ve bu hastaların dördü düşük kardiyak debiye bağlı exitus oldu. 
Tablo 2. Hasta gruplarının postoperatif özellikleri ve komplikasyonlar

\begin{tabular}{|c|c|c|c|}
\hline Gruplar & Homogreft & Contegra ${ }^{\circledR}$ Greft & $\begin{array}{c}\text { İstatistik yöntem, } \\
\text { p değeri }\end{array}$ \\
\hline Yoğun Bakımda Kalış Süresi (gün) & $1 \pm 0,04$ & $2,2 \pm 4$ & T test, $\mathrm{p}=0,04$ \\
\hline Hastanede Yatış Süresi (gün) & $5,8 \pm 1,5$ & $6,9 \pm 4$ & T test, $\mathrm{p}=0,18$ \\
\hline Hastane İçi Mortalite (n) & - & 4 & Fisher Exact test, $\mathrm{p}=0,56$ \\
\hline Total Mortalite (n) & - & 7 & Fisher Exact test, $\mathrm{p}=0,17$ \\
\hline \multicolumn{4}{|l|}{ Postoperatif Komplikasyonlar (n) } \\
\hline & Homogreft & Contegra ${ }^{\circledR}$ Greft & $\begin{array}{c}\text { İstatistik yöntem, } \\
\text { p değeri }\end{array}$ \\
\hline $\begin{array}{l}\text { Pnömoni } \\
\text { Düşük Kardiak Debi } \\
\text { Kalıcı AV Blok } \\
\text { Geçici AV Blok } \\
\text { Uzamış Mekanik Ventilasyon } \\
\text { Hemoraji } \\
\text { Plevral Efüzyon } \\
\text { Perikardial Efüzyon } \\
\text { Şilotoraks }\end{array}$ & $\begin{array}{l}2 \\
- \\
- \\
1 \\
- \\
1 \\
- \\
- \\
-\end{array}$ & $\begin{array}{l}4 \\
5 \\
2 \\
1 \\
2 \\
1 \\
1 \\
1 \\
1\end{array}$ & \\
\hline Total & 4 & 18 & Fisher Exact test, $\mathrm{p}=0,38$ \\
\hline
\end{tabular}

AV Blok: Atrio-ventriküler Blok

Hastane içi ölümlerin 4'ü de Contegra ${ }^{\circledR}$ Greft grubunda gerçekleşmesine rağmen istatistiksel olarak gruplar arasında anlamlı fark yoktu (Fisher exact test, $\mathrm{p}=0,56$ ). Her iki gruptaki total mortalite oranları benzerdi (Fisher exact test, $p=0,17)$. Kümülatif sağ kalım eğrileri KaplanMeier analizlerinden elde edilmiştir ve Şekil 1'de gösterilmiştir. Contegra ${ }^{\circledR}$ Greft grubu için tahmin edilen ortalama să kalım 5,6 yılken, homogreft grubunda yaklaşık 4 yıldır. Contegra ${ }^{\circledR}$ Greft grubunda 1 yıllık sağ kalım \%88 iken 5 yılda oran \%83'e düşmektedir (Kaplan-Meier metodu). Homogreft grubunda ise takip süresinde ölüm gerçekleşmemiştir.

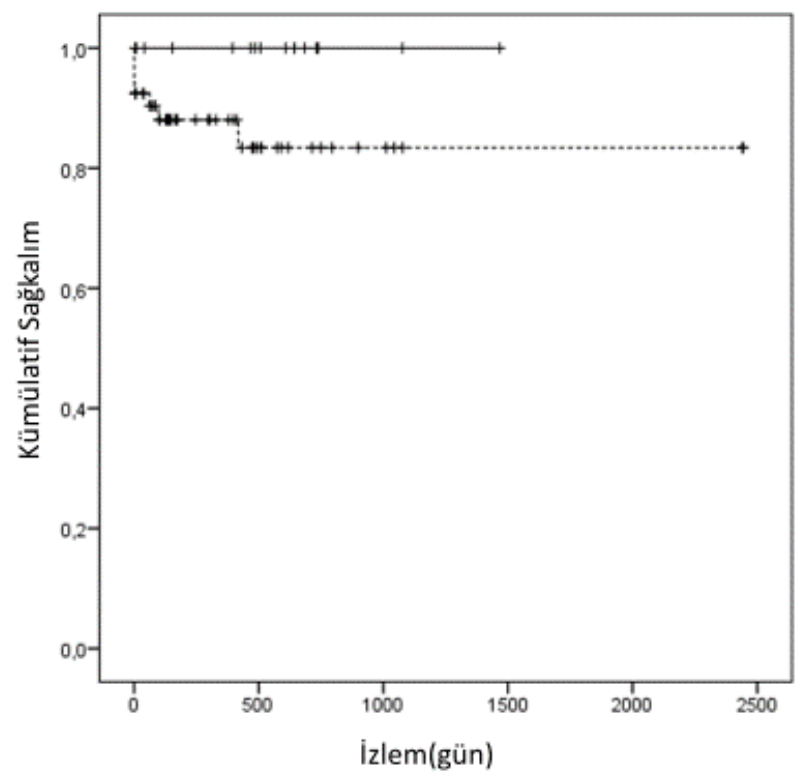


İzlemde pulmoner gradientin $>50 \mathrm{mmHg}$ olmasi; ciddi konduit darlığı ve ciddi pulmoner kapak yetmezliği gelişmesi ve endokardit olması reoperasyon gereksinimi kabul edildi. Takip süresinde hastaların hiçbirinde endokardit gelişmedi, literatürde Contegra ${ }^{\circledR}$ Greft kullanımıyla ilişkili olduğu bildirilen greft dilatasyonu hiçbir olguda gözlenmemiştir. Son izlemdeki ekokardiyografik değerler göz önüne alındığında pulmoner gradient ölçümlerinde gruplar arasında farkl1lık yoktu ( $t$ test, $\mathrm{p}=0,22$ ). Postoperatif nüks RVOT darlığ $\breve{1}_{1}$ Contegra ${ }^{\circledR}$ Greft grubunda 3 kișide gözlendi, bunların 2'sinde reoperasyon gerekti. Homogreft grubunda ise ciddi pulmoner gradient artışı 1 olguda gözlendi ve eşlik eden ciddi pulmoner kapak yetmezliği nedeniyle reoperasyon uyguland1. Reoperasyon gereksinimi açısından gruplar karşılaştırıldığında gruplar arasında anlamlı farklılık saptanmamıştır (Fisher exact test, $\mathrm{p}=1,0)$.

Multivariate Cox regresyon analizinde tanı, redo operasyonlar, cinsiyet, vücut yüzey alanı, preoperatif Creaktif protein (CRP) değeri ve lökosit sayısı mortalite için risk oluşturmazken, 1 yaş altında olmak mortalite için bağımsız bir risk faktörüydü $(\mathrm{p}=0,006, \operatorname{Exp}(\beta): 11.1$; güven aralı̆̆ $1 \% 95,1.99-62.04)$.

\subsection{Tartışma}

RVOT tamirlerinde birçok araştırmacı öncelikli olarak homogreftlerin konduit olarak tercih edilmesini önermektedir [6-8]. Bizim çalışmamızda ise hastaların \%25,4 'ünde homogreft kullanılmıştır. Bu durumun esas sebebi infantlara uygun boyda homogreftin bulunmasında yaşanan zorluktur. Hastaya uygun homogreft bulunamadığında 12 mm'e kadar küçük çapları bulunan, çalışmalarda erken ve orta dönemde homogreftlere benzer performans gösterdiği bildirilen Contegra ${ }^{\circledR}$ Greftler konduit olarak kullanılmaktadır. Çalışmamıza benzer şekilde, birçok araştırmacı RVOT tamirlerinde erken ve orta dönemde benzer komplikasyon ve mortalite oranları nedeniyle Contegra $\AA$ Greftleri homogrefte iyi bir alternatif olarak önermiştir [6-8,14]. Ancak, RVOT tamirlerinde spesifik olarak homogreft ve Contegra ${ }^{\circledR}$ Greft kullanılan olguların sağ kalımını ve postoperatif sonuçlarını karşılaştıran yayın sayısı azdır [3,15-17]. 71 vakayı içeren hasta serimizin literatüre katkı sağlayacağını düşünmekteyiz.

Birkaç çalışmada küçük yaşta operasyon geçiren ve küçük çapta yerleştirilen homogreftlerin daha erken bozulduğu bildirilmiştir [10,11] Erken bozulmayı önlemek için homogreftlerde kan grubu uygunluğunun göz önüne alınması gerektiği bazı yayınlarda vurgulanmıştır $[15,16]$. Bununla birlikte 3 yaştan sonra kan grubu uyumunun daha az önem taşıdığını bildiren yayınlar da mevcuttur. Çünkü hızlanmış kalsifikasyona sekonder konduit yetmezliği nedeniyle yapılan reoperasyonlar sıklıkla yenidoğan ve 3 yaş altındaki çocuklarda gözlenmektedir $[17,18]$. Bizim çalışmamızdaki olgularda homogreftlerin kısıtlı sayıda olması nedeniyle kan grubu uyumu her zaman sağlanamamıştır, ancak bu durum postoperatif mortalite ve reoperasyon oranlarına negatif bir etkide bulunmamıştır.

Çalışmamızda homogreft kullanılan grupta daha fazla oversize yapılabilmiştir ( $\mathrm{t}$ test, $\mathrm{p}<0,01$ ). Genel olarak hesaplanan pulmoner $Z$ değerinden en az $2 \mathrm{~mm}$ daha geniş çapta pulmoner konduit kullanılmıştır. Önceki çalışmalarda da çocuğun büyümesine adaptasyon açısından mümkün olan en fazla oversize oran1 önerilmiştir. Askovich B. ve ark., z skoru $\geq 2.7$ olanlarda pulmoner pozisyonda kriyoprezerve homogreft oversizing' inin uzun süre dayanıklılığı olumsuz etkilediğini bildirmiştir [19]. Bizim hasta serimizde, homogreft kullanılan grupta yalnızca bir hastada ciddi pulmoner kapak yetersizliği gelişti. $\mathrm{Bu}$ olgunun öncesinde de ciddi pulmoner hipertansiyonu mevcuttu. Tweddell ve ark. 205 hasta içeren serilerinde homogreft ile RVOT rekonstrüksiyonu uygulamışlardır. Küçük yaş, küçük homogreft çapı, donörün sıcak iskemi süresi ve yaşı büyük olan hastalarda aortik homogreft kullanımının homogreft ömrünü olumsuz yönde etkilediğini bildirmişlerdir. Hastanın büyümesiyle birlikte homogreft disfonksiyonun gelişebileceğini bu sebeple mümkün olan en büyük çaptaki greftin yerleştirilmesini önermişlerdir. Ayrica, reoperasyonlarda kullanılan homogreftlerin ilk operasyonda kullanılanlara göre daha hızlı kalsifiye olduğunu gözlemlemişlerdir [7].

Homogreft kullanılarak RVOT tamiri uygulanan 272 hastalık bir seride ortalama izlem süresi 5,7 yıldır. Sağ kalım oranlarını sırasıyla bir yılda $\% 96,5$, beş yılda $\% 95$ ve on y1lda \%94 olarak bildirmişlerdir. Greft eksizyonu olmaksızın sağ kalım oranlarını ise sırasıyla 1 yılda \%99, beş yılda $\% 94$ ve on yılda $\% 81$ bildirmişlerdir. Multivaryans analizde bizim çalışmamıza benzer şekilde küçük çapta greft yerleştirilmesinin reoperasyon için bağımsı risk faktörü olduğunu belirtmişlerdir. Çalışmalarında kan grubu uyumu ve redo homogreft kullanımının homogreft ömrüne belirgin etkisini gösterememişlerdir [9].

Cristensen ve arkadaşları ABO kan grubu uyumlu kriyoprezerve homogreftlerin Contegra ${ }^{\circledR}$ Greftten daha uzun sağ kalım oranlarına sahip olduğunu, bununla birlikte Contegra ${ }^{\circledR}$ Greftlerin sağ kalımının ise kan grubu uyumuna bakılmaksızın yerleştirilen homogreftlerden orta dönemde daha iyi olduğunu bildirmişlerdir [17].

Bizim serimizde erken dönem ölümlerin (4 hasta) tümü, Contegra ${ }^{\circledR}$ greft grubunda gerçekleşmişti ve bu hastaların üçü bir yaş altındaydı. Bu oran European Contegra Multicentre Study'ye göre biraz yüksektir. Ancak bu farklılığın, üç hastanın da truncus arterteriosus tanılı olmasından kaynaklandığını düşünmekteyiz. European Contegra Multicentre Study ve 170 hasta içeren Dave H. ve ark. nın çalışması Contegra ${ }^{\circledR}$ Greft sonuçlarını sunan geniş hasta serisine sahip yayınlardandır. $\mathrm{Bu}$ çalışmalarda, Contegra grefterin erken dönemde mortalite oranları çok iyi bulunmuş ve orta dönemde ise homogreftlerin sonuçlarıyla karşılaştırılabilir olduğu saptanmıştır. $\mathrm{Bu}$ nedenle Contegra ${ }^{\circledR}$ Greftlerin RVOT tamirlerinde homogreftlere iyi bir alternatif olabileceği belirtilmiştir. Contegra ${ }^{\circledR}$ Greftlerin en büyük avantajı istenen boyuta kolayca 
ulaşılabilir olmasıdır [20,21]. Türkiye'de homogreft bankası sınırlı sayıdadır, bu nedenle RVOT tamirlerinde son yıllarda Contegra ${ }^{\circledR}$ Greft daha yaygın oranda kullanılmaktadır. Çalışmamızda Contegra ${ }^{\circledR}$ greft grubunun sağ kalımı 1 yılda \%88 iken, 5 yılda \%83 saptanmıştır. Orta dönemdeki sağ kalımlar European Multicentre Study ile $(\% 86,5 \pm 2,7)$ benzer oranlardadır. Çalışmamızda Contegra ${ }^{\circledR}$ Greftlerlerde dilatasyon veya endokardit saptanmamıştır. Contegra ${ }^{\circledR}$ Greft stenozu 3 hastada $(\% 5,6)$ gözlenmiştir ve bunların ikisine reoperasyon gerekmiştir. Postoperatif dönemde tekrarlayan girişimler sıklıkla konduit stenozlarını rahatlatmak için yapılırken, kapak yetmezlikleri genç erişkin döneme kadar iyi tolere edilmektedir [17]. Hidentu D. ve arkadaşları $16 \mathrm{~mm}$ altındaki çapların, pulmoner hipertansiyonun ve erken yaştaki operasyonların ( $<2$ yaş) Contegra ${ }^{\circledR}$ Greft replasmanı için bağımsız risk faktörleri olduğunu bildirmiştir [21]. Diğer çalışmalarda greft çapı $<16 \mathrm{~mm}$ ve $<1$ yaş operasyonları erken eksplantasyon için bağımsız risk faktörü olarak saptamışlardır [20,22]. Bizim serimizde erken reoperasyon gerektiren hasta olmamıştır.

Geç dönemde ise reoperasyona neden olan en önemli problemler pulmoner kapakta yetmezlik, konduitte darlık oluşması veya $>50 \mathrm{mmHg}$ gradient gelişmesi ve endokardittir. Yakın dönemde yayınlanan bir çalışmada Contegra ${ }^{\circledR}$ Greft kullanılarak uygulanan RVOT tamirlerinde diğer konduitlere kıyasla daha fazla infektif endokardit gözlendiği bildirilmiştir (Contegra ${ }^{\circledR}$ Greft'de $\% 5,4$ iken diğerlerinde $\% 1,2$ p $<0.0001)$ [23]. Çalışmamızda takipte hiçbir hastada endokardit gözlenmemiştir. Contegra ${ }^{\circledR}$ Greft grubundaki iki hastada 3. derece pulmoner yetmezlik ve ciddi gradient artış1 nedeniyle reoperasyon uygulanmıştır. Henüz konduit dejenerasyonu gelişmemiş olsa da infantların büyümesiyle birlikte konduit replasmanı gerekebilmektedir bu nedenle pulmoner kapakta basınç gradienti, kapak yetmezliği, greft dilatasyonu ve ventrikül çapları, pulmoner arter basıncının yakınen izlenebilmesi için ekokardiyografi ile takipleri önem taşımaktadır.

Son yıllarda uzak doğu ülkelerinden yapılan yayınlarda sığır perikardial prostetik kapaklı konduit kullanımı ve PTFE greft içerisine fan şeklinde dikilen yaprakçıklarla oluşturulan konduitlerin de RVOT tamirinde kullanımı önerilmiştir. Hao C. ve ark. Contegra ${ }^{\circledR}$ Greft ve sığır perikardial prostetik kapaklı hastaları karşılaştırmışlardır. Tekrar girişim olmaksızın sağ kalımı 1 y1l da \%94,1 ve 5 yılda \%60,9 olarak bildirmişlerdir. Sığır juguler ven konduitlerinde stenozun daha çok konduitin distal kısmında geliştiğini, sı ğır perikardial kapaklı konduitlerde ise valvüler veya yaygın stenozun görüldüğünü; kapak yetmezliğinin ve endokarditin ise gruplarda benzer oranlarda görüldüğünü bildirmişlerdir [24]. Miyazaki T ve ark. PTFE greft içerisindeki, fan şekilli PTFE kapakçıkların olduğu greftle RVOT tamiri uygulanan 902 hastalık seride sağ kalımı sırasıyla 1 yılda $\% 96,1,5$ ve 10 yılda \%95,3 bildirmişlerdir. Konduit replasmanı olmaksızın sağ kalım 5 yılda \%96,3, 10 yılda ise \%87,4 saptanmıştır. PTFE konduitin hidrodinamik ölçümlerde iyi bir akım sağladığını ve uzun dönemde kapakçılarda yetmezliğin daha az görüldüğünü bildirmişlerdir ve bu durumun uzun dönemde Contegra $\AA$ Greftlere ve homogreftlere avantaj sağlayabileceğini bildirmişlerdir [12]

Çalışmamıza benzer olarak, yakın dönemde Poinot ve ark. tarafindan yayınlanan RVOT tamirlerinde Contegra greft ve Homogreftleri karşılaştırıldığı bir olgu kontrol çalışmasında her iki konduit, postoperatif komplikasyonlar, yoğun bakımda kalış süreleri, hastanede yatış süreleri ve mortalite bakımından benzer bulunmuştur. Ortalama \%2,3 civarında düşük bir mortaliteyle her iki tip konduitin de güvenle kullanılabileceğini bildirmişlerdir [25].

Çalışmamızın kısıtlılıkları; organ bağıșı sayısının az olması nedeniyle homogreft ile RVOT replasmanı sayısının Contegra ${ }^{\circledR}$ Greft replasmanlarına göre daha düşük olması ve hastaların daha uzun dönem takiplerinin henüz tamamlanmamış olmasıdır.

\section{Sonuç}

RVOT darlıklarının tamirinde Contegra greftler, homogreftlerin iyi bir alternatifidir. Contegra ${ }^{\circledR}$ Greftler ve homogreftlerin uzun dönem sağ kalımına ilişkin randomize kontrollü çalışmaların yetersizliği nedeniyle greft seçiminde önceliğe dair kanıt düzeyi yüksek veriler henüz yoktur. Çalışmamızda, her iki konduit greft ile erken ve orta dönemde benzer fonksiyonel kapasite ve sağ kalım oranları saptanmıştır. Hastaya uygun homogrefte ulaşılamadiğı durumlarda Contegra ${ }^{\circledR}$ Greftler, RVOT rekonstrüksüyonunda güvenle kullanılabilir.

\section{Teşekkür ve Bilgilendirme}

Bu araştırma makalesi Dilşad Amanvermez Şenarslan'ın "Sağ ventrikül çıkış yolu darlıklarının tamirinde homogreft ve Contegra $\AA$ greft (ksenogreft) kullanılan hastaların sağ kalımının karşılaştırılması" konulu uzmanlık tez çalışması sonuçlarını içermektedir. Çalışma, Ege Üniversitesi Tıp Fakültesi Kalp Damar Cerrahisi Anabilim Dalı'nda gerçekleştirilmiştir. Makale yazım süresinde yazarların çalıştı̆̆ 1 kurum değiştiğinden başlıkta güncel kurum bilgileri verilmiştir.

\section{Referanslar}

1. Breymann, T, Thies, W.R, Boethig, D, Goerg, R, Blanz, U, Koerfer, $\mathrm{R}$, Bovine valved venous xenografts for RVOT reconstruction: results after 71 implantations, European Journal of Cardiothoracic Surgery, 2002, 21(4), 703-10.

2. Brown, J.W, Ruzmetov, M, Rodefeld, M.D, Vijay, P, Darragh, R.K, Valved bovine jugular vein conduits for right ventricular outflow tract reconstruction in children: an attractive alternative to pulmonary homograft, The Annals of Thoracic Surgery, 2006, 82(3), 909-16.

3. Boethig, D, Thies, W.R, Hecker, H, Breymann, T, Mid term course after pediatric right ventricular outflow tract reconstruction: a comparison of homografts, porcine xenografts and Contegras, European Journal of Cardiothoracic Surgery, 2005, 27(1), 58-66.

4. Pearl, J.M, Cooper, D.S, Bove, K.E, Manning, P.B, Early failure of the Shelhigh pulmonary valve conduit in infants, Annals of Thoracic Surgery, 2002, 74(2), 542-8, discussion 548-549.

5. Ross, D.N, Somerville, J, Correction of pulmonary atresia with a homograft aortic valve, Lancet, 1966, 2(7479), 1446-7. 
6. Homann, M, Haehnel, J.C, Mendler, N, Paek, S.U, Holper, K, Meisner, $\mathrm{H}$ et al, Reconstruction of the RVOT with valved biological conduits: 25 years experience with allografts and xenografts, European Journal of Cardiothoracic Surgery, 2000, 17(6), 624-30.

7. Tweddell, J.S, Pelech, A.N, Frommelt, P.C, Mussatto, K.A, Wyman, J.D, Fedderly, R.T, et al, Factors affecting longevity of homograft valves used in right ventricular outflow tract reconstruction for congenital heart disease, Circulation, 2000, 102(19 Suppl 3), III130135 .

8. Lange, R, Weipert, J, Homann, M, Mendler, N, Paek, S.U, Holper, $\mathrm{K}$, et al, Performance of allografts and xenografts for right ventricular outflow tract reconstruction, Annals of Thoracic Surgery, 2001, 71(5 Suppl), S365-367.

9. Meyns, B, Jashari, R, Gewillig, M, Mertens, L, Komárek, A Lesaffre, E, et al, Factors influencing the survival of cryopreserved homografts. The second homograft performs as well as the first, European Journal of Cardiothoracic Surgery, 2005, 28(2), 211-6, discussion 216

10. Javadpour, H, Veerasingam, D, Wood, A.E, Calcification of homograft valves in the pulmonary circulation -- is it device or donation related? European Journal of Cardiothoracic Surgery 2002, 22(1), 78-81.

11. Butany, J, Ahluwalia, M.S, Nair, V, David, T.E, Cryopreserved pulmonary homograft: postimplant changes, Cardiovascular Pathology, 2004, 13(1), 59-61.

12. Miyazaki T, Yamagishi M, Maeda Y, Taniguchi S, Fujita S, Hongu $\mathrm{H}$, Yaku $\mathrm{H}$, Long-term outcomes of expanded polytetrafluoroethylene conduits with bulging sinuses and a fanshaped valve in right ventricular outflow tract reconstruction, Annals of Thoracic and Cardiovascular Surgery, 2018, 155(6), 2567-2576.

13. Raja, S.G, Contegra conduit: current outcomes and concerns, Expert Review of Cardiovascular Therapy, 2006, 4(5), 721-30.

14. Carrel, T, Bovine valved jugular vein (Contegra) to reconstruct the right ventricular outflow tract, Expert Review of Medical Devices, 2004, 1(1), 11-9

15. Sierra, J, Christenson, J.T, Lahlaidi, N.H, Beghetti, M, Kalangos, A, Right ventricular outflow tract reconstruction: what conduit to use? Homograft or Contegra? Annals of Thoracic Surgery, 2007, 84(2), 606-10, discussion 610-611.

16. Bové, T, Demanet, H, Wauthy, P, Goldstein, J.P, Dessy, H, Viart, P, et al, Early results of valved bovine jugular vein conduit versus bicuspid homograft for right ventricular outflow tract reconstruction, The Annals of Thoracic Surgery, 2002, 74(2), 536-41.

17. Christenson, J.T, Sierra, J, Colina Manzano, N.E, Jolou, J, Beghetti, M, Kalangos, A, Homografts and xenografts for right ventricular outflow tract reconstruction: long-term results, The Annals of Thoracic Surgery, 2010, 90(4), 1287-93.

18. Christenson, J.T, Vala, D, Sierra, J, Beghetti, M, Kalangos, A, Blood group incompatibility and accelerated homograft fibrocalcifications, Journal of Thoracic and Cardiovascular Surgery, 2004, 127(1), 24250

19. Askovich, B, Hawkins, J.A, Sower, C.T, Minich, L.L, Tani, L.Y, Stoddard, G, et al, Right ventricle-to-pulmonary artery conduit longevity: is it related to allograft size? The Annals of Thoracic Surgery, 2007, 84(3), 907-11, discussion 911-912.

20. Breymann, T, Blanz, U, Wojtalik, M.A, Daenen, W, Hetzer, R, Sarris, G, et al, European Contegra multicentre study: 7-year results after 165 valved bovine jugular vein graft implantations, The Thoracic and cardiovascular surgeon, 2009, 57(5), 257-69.

21. Dave, H, Mueggler, O, Comber, M, Enodien, B, Nikolaou, G Bauersfeld, U, et al, Risk factor analysis of 170 single-institutional contegra implantations in pulmonary position, The Annals of Thoracic Surgery, 2011, 91(1), 195-302, discussion 202-203.

22. Dearani, J.A, Danielson, G.K, Puga, F.J, Schaff, H.V, Warnes, C.W, Driscoll, D.J, et al, Late follow-up of 1095 patients undergoing operation for complex congenital heart disease utilizing pulmonary ventricle to pulmonary artery conduits, The Annals of Thoracic Surgery, 2003, 75(2), 399-410, discussion 410-411.

23. Sharma, A, Cote, A.T, Hosking, M.C.K, Harris, K.C, A Systematic Review of Infective Endocarditis in Patients With Bovine Jugular Vein Valves Compared With Other Valve Types, JACC: Cardiovascular Interventions, 2017, 10(14), 1449-58.

24. Chen, H, Shi, G, Qiu, L, Wang, S, Chen, H, Xu, Z, Outcomes of Prosthetic Valved Conduits for Right Ventricular Outflow Tract Reconstruction, Pediatric Cardiology, 2019, 40(4), 848-856.
25. Poinot, N, Fils, J.F, Demanet, H, Dessy, H, Biarent, D, Wauthy, P, Pulmonary valve replacement after right ventricular outflow tract reconstruction with homograft vs Contegra $\AA$ : a case contro comparison of mortality and morbidity, Journal of Cardiothoracic Surgery, 2018, 13(1), 8

http://edergi.cbu.edu.tr/ojs/index.php/cbusbed isimli yazarın CBU-SBED başlıklı eseri bu Creative Commons Alınt1-Gayriticari4.0 Uluslararas1 Lisans1 ile lisanslanmıștır.

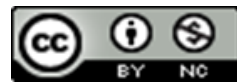

